\title{
Synthesis A Reagent [3-Hydroxy 4- (1-Azo-2,7-Dihydroxy) Naphthalene Sulfonic Acid] and Used it for Determination of Flourometholone in Bulk and Pharmaceutical Formulations by Spectrophotometric Method
}

Amir Alhaj Sakur ${ }^{1}$, Malek Okdeh ${ }^{2 *}$ and Banana Al Fares ${ }^{1,2}$

${ }^{1}$ Department of Analytical and Food Chemistry, Faculty of Pharmacy, University of Aleppo, Syria

${ }^{2}$ Department of Analytical Chemistry, Faculty of Science, Teshreen University, Lattakia, Syria

\begin{abstract}
A Reagent [3-hydroxyl 4- (1-azo-2,7-dihydroxyl) naphthalene Sulfonic acid] (AAN) ] has been synthesized for the determination of flourometholone (FLU) in pure form and in ophthalmic suspensions (drops) by a simple, sensitive and extraction-free spectrophotometric method. The method is based on the formation of yellow colored complex between FLU and ANN maximum at $416 \mathrm{~nm}$. The stoichiometry of the complex in either form was found to be (1:1). Reaction conditions were optimized to obtain the maximum color intensity. Beer's law was obeyed in the concentration ranges of $0.5-17.0 \mu \mathrm{g} / \mathrm{mL}$. The limit of quantification (LOQ) was $0.14 \mu \mathrm{g} / \mathrm{mL}$ and molar absorptivity $(\varepsilon)$ values was $38555 \mathrm{~L} /$ $\mathrm{moL}^{-1} \mathrm{~cm}^{-1}$. The proposed method has been applied successfully to the analysis of FLU in pure form and in its dosage forms and no interference was observed from common excipients present in pharmaceutical formulations. Statistical comparison of the results with the reference method showed excellent agreement and indicated no significant difference in accuracy and precision.
\end{abstract}

Keywords: Spectrophotometry; Synthesis; Flourometholone

\section{Introduction}

Flourometholone (FLU) Systematic name is 9-Fluoro-11 $\beta$, 17-dihydroxy-6a-methylpregna-1,4-diene-3,20-dione (Figure 1). Flourometholone is an ophthalmic suspension $0.1 \%$ which is a topical anti-inflammatory agent for ophthalmic use. Flourometholone is indicated for the treatment of corticosteroid-responsive inflammation of the palpebral and bulbar conjunctiva, cornea and anterior segment of the globe [1].

The assay of FLU in pure and dosage forms requires more investigation. The different analytical methods that have been reported for its determination include HPLC [2], with UV by using 1,4-Dihydrazinophthalazine as reagent [3], derivative spectrophotometry and HPLC [4], UV spectrophotometric by using methanol and sulfonic acid Buffer $\mathrm{pH}=3$ [5], HPTLC [6].

The aim of this work is to synthesis organic reagents and used it in spectroscopic analytical study for the determination of Flourometholone (FLU) through complexion with new complex dye [3- hydroxyl 4-(1- azo -2, 7- hydroxyl) naphthalene Sulfonic acid] (AAN) (Figure 2) in dichloromethane medium has been applied, either in laboratory samples or in dosage forms, without any interference from the excipients that are normally present in formulations.

\section{Experimental}

\section{Apparatus}

Infrared Spectrometer (FTIR) from company Bruker (Germany) model ALPHA, (LC-MS) from company (Shimadzu) UFLC Shimadzu model LC MS-2010 EV. Melting point KRUSS (Germany) model CEKSP1, spectrophotometric measurements were made in Jasco company (Japan) model V650, UV-Visible spectrophotometer with $1.00 \mathrm{~cm}$ quartz cells. Ultrasonic processor model power sonic 405 was used to sonicate the sample solutions.

The diluter pipette model DIP-1 (Ependorf), having $100 \mu \mathrm{L}$ sample syringe and five continuously adjustable pipettes covering a volume range from 20 to $5000 \mu \mathrm{L}$ (model Piptman P, Gilson), were used for preparation of the experimental solutions.

\section{Reagents and solutions}

Pharmaceutical form of Flourometholone (FLU 99.88\%) was received from Univision Pharmaceutical Co. Ltd. (China). A stock solutions of FLU $\left(2.0 \times 10^{-4} \mathrm{M}\right)$ were prepared by dissolving the appropriate weight of FLU in $70 \mathrm{~mL}$ dichloromethane and the volume were diluted to the mark $100 \mathrm{~mL}$ in calibrated flask with dichloromethane and take from the last solution $1 \mathrm{~mL}$ to the calibrated flask $10 \mathrm{~mL}$ too with the same solvent. Working standard solutions were prepared from suitable dilution of the standard stock solution.

Working standard solution was prepared daily by added different volumes of stock solutions to $2 \mathrm{~mL}$ of reagent BCG $\left(1 \times 10^{-4} \mathrm{M}\right)$ diluting to $10 \mathrm{~mL}$ with dichloromethane.

The concentration of FLU (0.5, 1.0, 2.0, 3.0, 5.0, 7.0, 9.0, $12.0,15.0,17.0 \mu \mathrm{g} . \mathrm{mL}^{-1}$ ) were used for the analysis of FLU by the spectrophotometric method. The method was based on formatting complex between Synthesis AAN dyes and FLU in dichloromethane medium. The colored product was quantified spectrophotometrically using absorption bands at $416 \mathrm{~nm}$ for complex of (FLU-AAN) and at $416 \mathrm{~nm}$ for (FLU-AAN).

A dye [3- hydroxyl 4-(1- azo -2,7- di hydroxyl) naphthalene Sulfonic acid] (AAN) $\left(1 \times 10^{-4} \mathrm{M}\right)$ prepared by shaking $10.42 \mathrm{mg}$ of AAN dye in $100 \mathrm{~mL}$ dichloromethane to dissolve and made up to mark with dichloromethane in a $250 \mathrm{~mL}$ calibrated flask.

Flourometholone ophthalmic suspensions brand name is Fumeron, Fumeron Fort (Rama Pharma Company for pharmaceutical industry,

*Corresponding author: Malek Okdeh, Department of Analytical Chemistry, Faculty of Science, Teshreen University, Lattakia, Syria, Tel: +9634135245 E-mail: dr.malekokdeh@yahoo.com

Received February 29, 2016; Accepted March 23, 2016; Published March 28 2016

Citation: Sakur AA, Okdeh M, Al Fares B (2016) Synthesis A Reagent [3-Hydroxy 4(1-Azo-2,7-Dihydroxy) Naphthalene Sulfonic Acid] and Used it for Determination of Flourometholone in Bulk and Pharmaceutical Formulations by Spectrophotometric Method. Mod Chem appl 4: 177. doi:10.4172/2329-6798.1000177

Copyright: ( 2016 Sakur AA, et al. This is an open-access article distributed under the terms of the Creative Commons Attribution License, which permits unrestricted use, distribution, and reproduction in any medium, provided the original author and source are credited. 
Citation: Sakur AA, Okdeh M, Al Fares B (2016) Synthesis A Reagent [3-Hydroxy 4- (1-Azo-2,7-Dihydroxy) Naphthalene Sulfonic Acid] and Used it for Determination of Flourometholone in Bulk and Pharmaceutical Formulations by Spectrophotometric Method. Mod Chem appl 4: 177. doi:10.4172/2329-6798.1000177

Page 2 of 4<smiles>CC(=O)[C@]1(O)CC[C@H]2[C@@H]3C[C@H](C)C4=CC(=O)C=C[C@]4(C)[C@]3(F)[C@H](O)C[C@]21C</smiles>

Figure 1: Structure of FLU

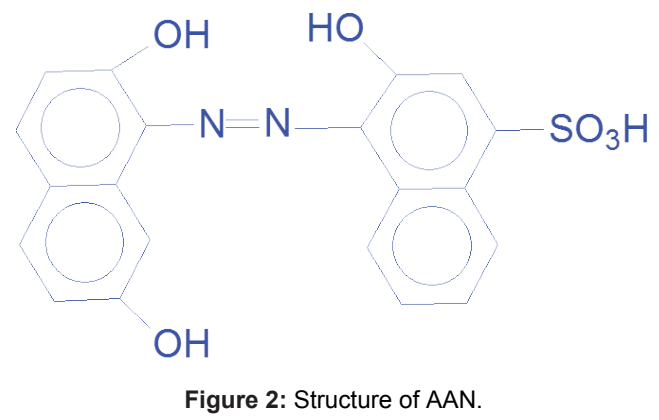

Syria) containing $100 \mathrm{mg}$ and $250 \mathrm{mg}$ in $1 \mathrm{~mL}$, Fludrop, Fludrop Fort (Obary Company, Syria) containing $100 \mathrm{mg}$ and $250 \mathrm{mg}$ in $1 \mathrm{~mL}$, Methoflor (Dyamond pharmaceutical industry, Syria) containing $100 \mu \mathrm{g}$ in $1 \mathrm{~mL}$. And also there is FLORA-T (Medico pharmaceutical industry, Syria) containing $100 \mu \mathrm{g}$ in $1 \mathrm{~mL}$ from local medical stores. All reagents and solvents were of analytical grade.

\section{Synthesis reagent AAN}

The synthesis Reagent is AAN according the following diazotization reaction (Figure 3) [7].

\section{Spectrophotometric procedure}

Increasing volumes of FLU working standard solution were transferred into series of $10 \mathrm{~mL}$ volumetric flasks that contain $2 \mathrm{~mL}$ of AAN reagent $\left(1 \times 10^{-4} \mathrm{M}\right)$. Solutions were mixed gently and allowed to stand at room temperature. Volumes were made up to mark with dichloromethane and mixed before the spectra were recorded at 416 $\mathrm{nm}$ against reagent blank that had been treated similarly.

\section{Determination of FLU/Dye stoichiometric relationship}

The composition ratio of drug FLU to dye (AAN) of the colored complex was determined using the molar ratio and continuous variation methods.

\section{Procedure for pharmaceutical samples}

An accurately volume amount of the sterile ophthalmic suspensions (drops) equivalent to $75.29 \mu \mathrm{g}$ of FLU was transferred into $10 \mathrm{~mL}$ volumetric flask and added $2 \mathrm{~mL}$ of AAN, and diluted with dichloromethane up to the mark. After then the spectra was recorded at $416 \mathrm{~nm}$ against reagent blank.

\section{Results and Discussion}

\section{Dye structure identification (AAN)}

Physical properties: Weight: $410 \mathrm{~g} / \mathrm{mol}$. Appearance: the dye (AAN) appears red color powder. The solutions in water are stable. Solubility: The dye (AAN) free Soluble in water, alcohol, dimethylformamide; insoluble in acetone. Melting point: $111-116^{\circ} \mathrm{C}$.

UV-Visible spectrophotometry: The Figure 4 shows the spectra of solution (0.01\%) of dye AAN in ethanol at $\lambda_{\text {max }}=498 \mathrm{~nm}$.

IR Spectrophotometry: The Figure 5 shows the FTIR spectra of potassium bromide disk the Distinctive peak

$$
\begin{aligned}
& v=1513 \mathrm{~cm}^{-1}(\mathrm{~N}=\mathrm{N}) \\
& v=3411 \mathrm{~cm}^{-1}(\mathrm{O}=\mathrm{H}) \\
& v=1620 \mathrm{~cm}^{-1}(\mathrm{C}=\mathrm{C})
\end{aligned}
$$

LC-MS: The Figure 6 shows the separation chromatogram of AAN by using mobile phase (Water: Methanol) (30:70); after separation MS achieved after applying negative and positive volt (Figure 7). The result shows that the weight of reagent is $410 \mathrm{~g} / \mathrm{mol}$.

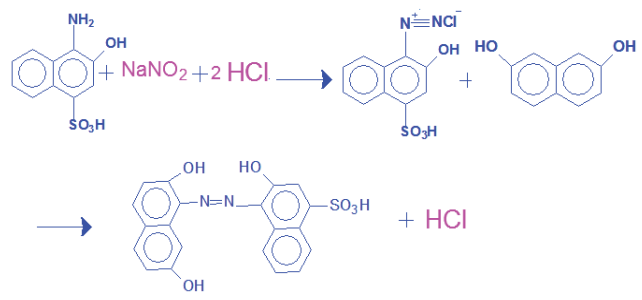

Figure 3: Diazotization reaction of AAN

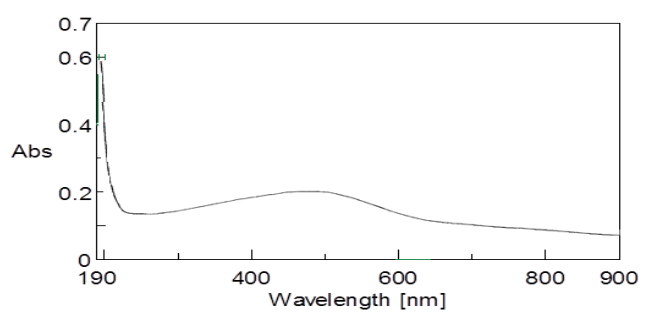

Figure 4: Spectra of AAN in spectrophotometry in ethanol $10 \%(\mathrm{v} / \mathrm{v})$.

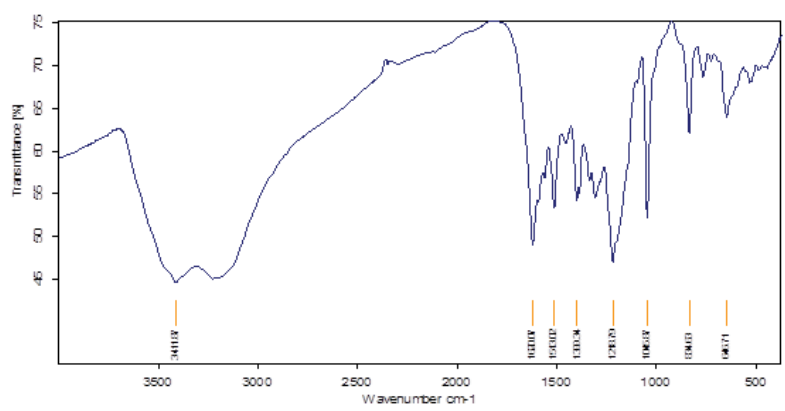

Figure 5: FTIR Spectra of AAN

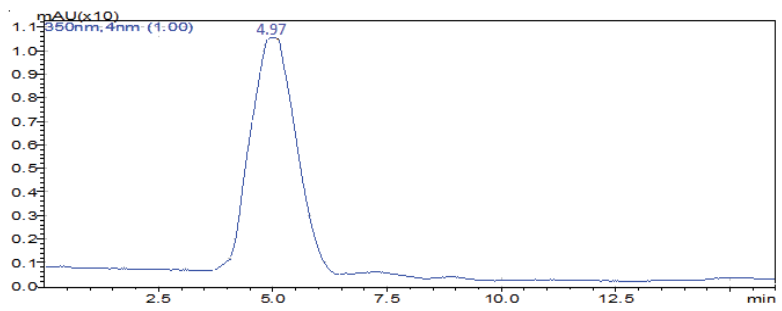

Figure 6: Separation chromatogram of AAN by LC-MS 
Citation: Sakur AA, Okdeh M, Al Fares B (2016) Synthesis A Reagent [3-Hydroxy 4- (1-Azo-2,7-Dihydroxy) Naphthalene Sulfonic Acid] and Used it for Determination of Flourometholone in Bulk and Pharmaceutical Formulations by Spectrophotometric Method. Mod Chem appl 4: 177. doi:10.4172/2329-6798.1000177

Page 3 of 4

\section{Optimization of reaction conditions for (FLU-AAN)}

Solvent effect: In order to select a suitable solvent for preparation of the reagent solutions used in the study, the reagents were prepared separately in different solvents such as, chloroform methanol, dichloromethane and dichloromethane, and the reaction of FLU with AAN was followed. Dichloromethane was suited for the complete forming with AAN. Similarly, the effect of the diluting solvent was studied for the method and the results showed that none of the solvents except dichloromethane formed sensitive and stable colored in method. Therefore, dichloromethane was used for dilution throughout the investigation. Dichloromethane was preferred as the most suitable solvent because in this medium, the reagent blank gave negligible blank absorbance and the formed ion-pair complex was found to exhibit higher sensitivity and stability. In other solvents, the reagent blank yielded high absorbance values.

Effect of reaction time and stability: The optimum reaction time for the development of color at ambient temperature $\left(25 \pm 2^{\circ} \mathrm{C}\right)$ was studied and it was found that the complex forming after added the reagent and no time necessary for the complete formation of ion-pair complexes in a method giving yellow colored solutions have maximum absorbance at $\lambda_{\text {max }}$ The formed color was stable for more than $24 \mathrm{~h}$ in method.

Effect of dye concentration: The influence of the concentration of AAN on the intensity of the color developed at the selected wavelength and constant drug concentration was studied. As shown in Figure 8, the constant absorbance readings were obtained between $(0.25-5 \mathrm{~mL})$ of $\left(1 \times 10^{-4} \mathrm{M}\right)$ of AAN, $2 \mathrm{~mL}$ of each AAN was used for methods A and $\mathrm{B}$, respectively.

Stoichiometric ratio: Molar ratio method [8]: The stoichiometry of (FLU: Dye) complex by molar ratio method according to following equation: $A_{\max }=f([F L U] /[$ Dye $]$, confirms that the ratio of complex FLU:AAN is equal to 1:1 (Figure 9).

Job's method [9]: In order to establish the stoichiometry of FLU and dye (AAN) complex by Job's method of continuous variations was applied. The plot reached a maximum value at a mole fraction of 0.5 which indicated the formation of 1:1 (FLU: Dye) complex (Figure 10) between FLU and AAN.

\section{Validation of the proposed method}

Under the optimum experimental conditions, standard calibration curve was constructed at ten concentration levels $(n=5)$ (Figure 11). The correlation coefficient was 0.9999 for method A and 0.9998 indicating very good linearity, over the concentration range of 0.5 $17.0 \mu \mathrm{g} / \mathrm{mL}$. The intercept, slope, limit of detection (LOD), and limit of quantitation (LOQ) are summarized in Table 1. LOD and LOQ values were calculated as $3.3 \mathrm{~S}_{\mathrm{b}} / \mathrm{m}$ and $10 \mathrm{~S}_{\mathrm{b}} / \mathrm{m}$, respectively where molar absorptivity of regression (Table 1).

The results obtained are summarized in Table 2. The low values of Relative Standard Deviation (RSD) indicate good precision and reproducibility of the method. The average percent recoveries obtained were 98.70-101.53\% for AAN, indicating good accuracy of the method.

The repeatability of proposed methods were estimated by measuring five replicate samples of each concentration of flourometholone prepared in one laboratory on the same day. The precision expressed as the Relative Standard Deviation (RSD\%) ranged from $0.45 \%$ to $3.66 \%$ for the smallest concentration, indicating good precision (Table 2).

\section{Application to ophthalmic suspension (eye drops)}

The proposed method was applied to the determination of FLU in eye drops. The results in Table 3 showed that the methods are
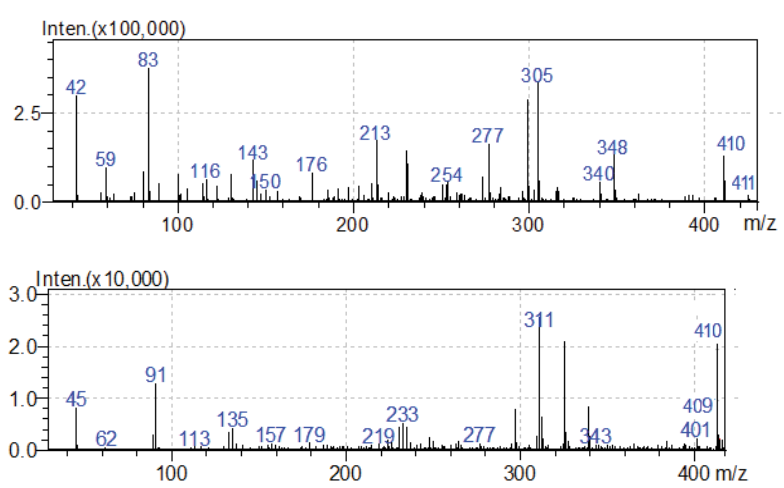

Figure 7: LC-MS Spectra of AAN.

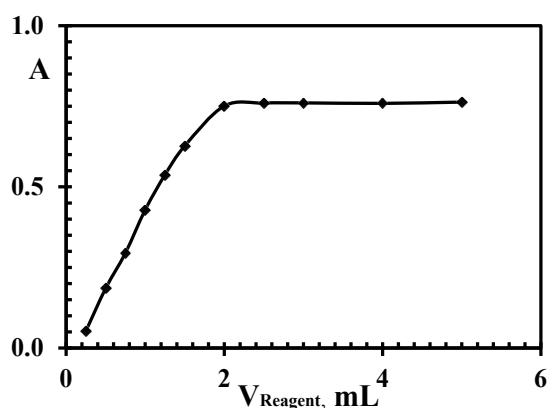

Figure 8: Effect of the volume added of dye (AAN) solution on the absorbance of FLU-Dye complex.

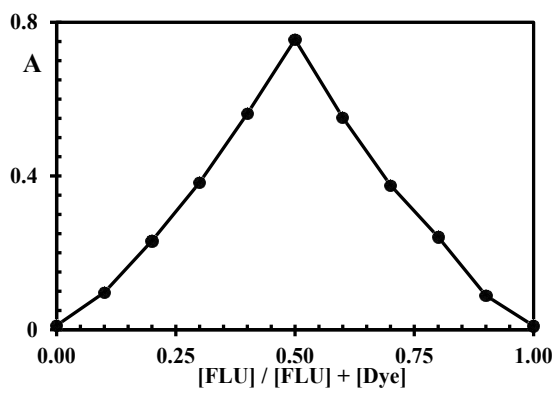

Figure 9: Molar ratio plots for (FLU-AAN) complex.

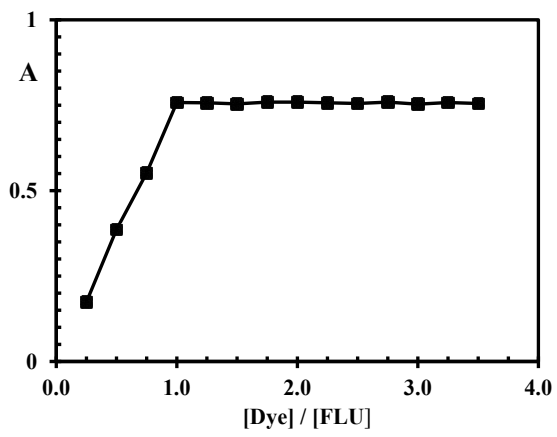

Figure 10: Continuous variations plots for (FLU-AAN) complex.

successful for the determination of ZMT and that the excipients in the dosage forms do not interfere. A statistical comparison of the results for determination of ZMT from the same batch of material by the proposed and reference method is shown in Table 4 . The results agreed 
Citation: Sakur AA, Okdeh M, Al Fares B (2016) Synthesis A Reagent [3-Hydroxy 4- (1-Azo-2,7-Dihydroxy) Naphthalene Sulfonic Acid] and Used it for Determination of Flourometholone in Bulk and Pharmaceutical Formulations by Spectrophotometric Method. Mod Chem appl 4: 177. doi:10.4172/2329-6798.1000177

Page 4 of 4

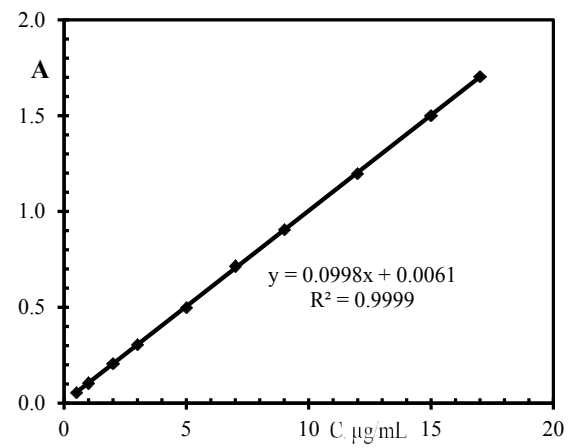

Figure 11: Calibration plot of FLU using AAN.

\begin{tabular}{|c|c|}
\hline Parameter & Result \\
\hline$\lambda_{\text {max }}(\mathrm{nm})$ & 416 \\
\hline Linear range $(\mu \mathrm{g} / \mathrm{mL})$ & $0.5-17.0$ \\
\hline Slope & 0.0998 \\
\hline Molar absorptivity $(\varepsilon), \mathrm{L} / \mathrm{moL} . \mathrm{cm}$ & $3.8555 \times 10^{4}$ \\
\hline Intercept & 0.0061 \\
\hline Correlation coefficient & 0.9999 \\
\hline Limit of detection $(\mu \mathrm{g} / \mathrm{mL})$ & 0.14 \\
\hline Limit of quantification $(\mu \mathrm{g} / \mathrm{mL})$ & 0.45 \\
\hline
\end{tabular}

Table 1: Statistics and analytical parameters of FLU determination by AAN.

\begin{tabular}{|c|c|c|c|c|c|}
\hline Taken FLU & aFound FLU & SD & $\mathbf{R S D} \%$ & $\begin{array}{c}\text { Confidence } \\
\text { limit }\end{array}$ & Recovery $\%$ \\
\hline $\mathbf{\mu g} / \mathbf{m L})$ & $\mathbf{( \mu \mathbf { g } / \mathbf { m L } )}$ & $\mathbf{( \mu \mathbf { g } / \mathbf { m L } )}$ & & & \\
\hline 0.5 & 0.50 & 0.018 & 3.60 & $0.50 \pm 0.022$ & 99.52 \\
\hline 1.0 & 1.00 & 0.020 & 2.04 & $1.00 \pm 0.025$ & 99.54 \\
\hline 2.0 & 1.99 & 0.024 & 1.20 & $1.99 \pm 0.030$ & 99.75 \\
\hline 3.0 & 3.00 & 0.030 & 1.00 & $3.00 \pm 0.037$ & 99.93 \\
\hline 5.0 & 4.94 & 0.055 & 1.11 & $4.94 \pm 0.068$ & 98.70 \\
\hline 7.0 & 7.11 & 0.030 & 0.42 & $7.11 \pm 0.037$ & 101.53 \\
\hline 9.0 & 9.01 & 0.036 & 0.40 & $9.01 \pm 0.045$ & 100.12 \\
\hline 12.0 & 11.96 & 0.066 & 0.55 & $11.96 \pm 0.082$ & 99.67 \\
\hline 15.0 & 14.98 & 0.139 & 0.92 & $14.98 \pm 0.172$ & 99.90 \\
\hline 17.0 & 17.01 & 0.076 & 0.45 & $17.01 \pm 0.095$ & 100.03 \\
\hline
\end{tabular}

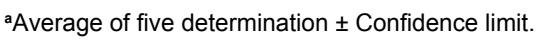

Table 2: Precision for determination of FLU in pure form using proposed method.

\begin{tabular}{|c|c|c|c|c|c|}
\hline Product & $\begin{array}{c}\text { Taken } \\
\text { FLU } \\
\boldsymbol{\mu g} / \mathbf{1} \mathbf{~ m L}\end{array}$ & $\begin{array}{c}\text { Found }^{*} \\
\mathbf{F L U} / \mathbf{1} \mathbf{~ m L}\end{array}$ & SD $(\boldsymbol{\mu g} / \mathbf{m l})$ & RSD\% & $\begin{array}{c}\text { Recovery } \\
\mathbf{R \%}\end{array}$ \\
\hline Fumeron & 10.00 & 99.28 & 0.04 & 0.56 & 99.28 \\
\hline Fumeron Fort & 250.00 & 251.57 & 0.05 & 0.65 & 100.63 \\
\hline Fludrop & 100.00 & 100.16 & 0.06 & 0.80 & 100.16 \\
\hline Fludrop Fort & 250.00 & 250.75 & 0.05 & 0.65 & 100.30 \\
\hline Methoflor & 100.00 & 101.58 & 0.07 & 0.95 & 101.58 \\
\hline Flora-T & 100.00 & 102.17 & 0.05 & 0.62 & 102.17 \\
\hline
\end{tabular}

aAverage and standard deviation of five determinations for the proposed method.

Table 3: Results of the estimation of FLU in eye drops

well with the label claim and also are in agreement with the results obtained by the reference method. Statistical analysis of the results using Student's t-test for accuracy and F-test for precision revealed no significant difference between the proposed and reference method at the $95 \%$ confidence level with respect to accuracy and precision.

Accuracy is judged by comparing the results obtained from the presently proposed method that has been applied on commercial ophthalmic drops, with those obtained from a reference method such as HPLC. The resulted values were statistically compared with each other Table 4 using t- and F-tests. With respect to t- and F-tests, no significant differences were found between the calculated values of both the proposed and the reported methods at $95 \%$ confidence level.

\section{Conclusion}

The proposed method for the estimation of FLU using synthesis reagent AAN are advantages over many of the reported methods. The methods are rapid, simple and have good sensitivity and accuracy. Proposed method makes use of simple reagent, which an ordinary analytical laboratory can afford. The high recovery percentage and low relative standard deviation reflect the high accuracy and precision of the proposed method. The method are easy, applicable to a wide range of concentration, besides being less time consuming and depend on simple reagent which are available, thus offering economic and acceptable methods for the routine determination of FLU in its formulations.

\begin{tabular}{|c|c|c|}
\hline \multirow[t]{2}{*}{ Product } & \multicolumn{2}{|c|}{${ }^{*}$ Recovery $\% \pm$ SD } \\
\hline & $\begin{array}{l}\text { Suggested method } \\
\text { Using AAN }\end{array}$ & Pharmacopoeial method \\
\hline $\begin{array}{c}\text { Fumeron } \\
100 \mu \mathrm{g} / 1 \mathrm{~mL}\end{array}$ & $\begin{array}{c}99.28 \pm 0.04 \\
t=1.29 \\
F=1.43\end{array}$ & $\begin{array}{c}100.86 \pm 0.98 \\
t=1.24\end{array}$ \\
\hline $\begin{array}{l}\text { Fumeron Fort } \\
250 \mu \mathrm{g} / 1 \mathrm{~mL}\end{array}$ & $\begin{array}{c}100.63 \pm 0.05 \\
t=2.48 \\
F=1.18\end{array}$ & $\begin{array}{c}101.11 \pm 0.45 \\
t=1.87\end{array}$ \\
\hline $\begin{array}{c}\text { Fludrop } \\
100 \mu \mathrm{g} / 1 \mathrm{~mL}\end{array}$ & $\begin{array}{c}100.16 \pm 0.06 \\
t=1.69 \\
F=1.12\end{array}$ & $\begin{array}{c}100.34 \pm 0.76 \\
t=1.97\end{array}$ \\
\hline $\begin{array}{l}\text { Fludrop Fort } \\
250 \mu \mathrm{g} / 1 \mathrm{~mL}\end{array}$ & $\begin{array}{c}100.30 \pm 0.05 \\
t=2.21 \\
F=1.61\end{array}$ & $\begin{array}{c}99.96 \pm 0.88 \\
t=1.95\end{array}$ \\
\hline $\begin{array}{c}\text { Methoflor } \\
100 \mu \mathrm{g} / 1 \mathrm{~mL}\end{array}$ & $\begin{array}{c}101.58 \pm 0.07 \\
t=1.72 \\
F=1.38\end{array}$ & $\begin{array}{c}101.21 \pm 0.54 \\
t=1.67\end{array}$ \\
\hline $\begin{array}{c}\text { Flora-T } \\
100 \mu \mathrm{g} / 1 \mathrm{~mL}\end{array}$ & $\begin{array}{c}102.17 \pm 0.05 \\
t=1.46 \\
F=1.52\end{array}$ & $\begin{array}{c}101.93 \pm 0.77 \\
t=1.83\end{array}$ \\
\hline
\end{tabular}

*Average of five determinations for four degree and confidence limit $95 \%, t=2.776$ $F=6.26$

Table 4: Comparative between tow suggested methods and pharmacopoeial method

\section{References}

1. Physician's Desk Reference (PDR) (2009) Micromedex Thomson Health Care 63rd USA

2. Jonvel P, Andermann G (1983) Determination of fluorometholone purity by very high-performance liquid chromatography. Analyst 108: 411-414

3. Altuntas TG, Korkmaz F, Nebioglu D (2000) Determination of tetrahydrozoline hydrochloride and fluorometholone in pharmaceutical formulations by HPLC and derivative UV spectrophotometry. Pharmazie 55: 49-52.

4. Vladimirov S, Cudina O, Agbab D, Zivanov-Stakic D (1996) Spectrophotometric Determination of Fluorometholone in Pharmaceuticals Using 1,4-Dihydrazinophthalazine. Anal Lett 29: 921-927.

5. Narendra A, Deepika D, Annapurna MM (2014) New Spectrophotometric Methods for the Quantitative Analysis of Fluorometholone in Ophthalmic Suspensions. Chem Sci Trans 3: 445-449.

6. Saleh SS, Lotfy HM, Hassan NY, Elgizawy SM (2013) A comparative study of validated spectrophotometric and TLC- spectrodensitometric methods for the determination of sodium cromoglicate and fluorometholone in ophthalmic solution. Saudi Pharm J 21: 411-421.

7. Tewari KS, Mehrotra SN, Vishnoi NK (1955) Organic Chemistry. Vikas Publishing House Pvt. Ltd.

8. Vosburgh WC, Cooper GR (1941) The Identification of Complex ions in Solution by Spectrophotometric measurements. J Am Chem Soc 63: 437-442.

9. Miller JC, Miller JN (1993) Statistics in Analytical Chemistry. 3rd edn. Ellis Horwood, Chichester, p: 119 